TRANS · núm. I9.I · 2015

MONOGRÁFICO · 109-129
El cometido del intérprete en un encargo de intervenciones telefónicas es sin duda arduo y complejo. En esta ocasión, y sin adentrarse en consideraciones ligadas a marcos jurídicos vigentes o en reflexiones deontológicas sobre el ejercicio de la interpretación en este preciso contexto, nos centraremos en el análisis de elementos puramente metodológicos que caracterizan este trabajo, como la hibridación de las modalidades de la disciplina operacional, la variabilidad constante de las partes implicadas, la diversificación de tareas o la consecuente readaptación del intérprete a la evolución de toda investigación judicial que, a menudo, impone continuos cambios en las estrategias de trabajo.

El presente artículo recoge algunas consideraciones introspectivas sobre la labor del intérprete de escuchas telefónicas en ejercicio; a partir de esta experiencia profesional, los objetivos que se persiguen son: identificar la disciplina de interpretación utilizada en escuchas telefónicas, analizar los elementos extra- e intracontextuales de su situación comunicativa genérica, y examinar las partes implicadas, tareas y funciones de las mismas, con la intención de asistir al intérprete en la difícil gestión de tan singular encargo.

PALABRAS CLAVE Interpretación judicial, escuchas telefónicas, interpretación bilateral, interpretación telefónica

\title{
Interpretar escuchas telefónicas en ámbito judicial: análisis descriptivo y metodología operacional
}

\section{Interpreting Wiretapped Conversations in the Judicial Setting: Descriptive Analysis and Operating Methodology}

The task of an interpreter of wiretapped conversations is hard and complex from various standpoints. Without entering into considerations about the current legal framework or deontological reflections on interpreting in judicial settings, in this paper we will focus on purely methodological features which characterise this kind of assignment, such as the hybridisation of operating modes, the constant variability of the parties involved, the diversification of tasks or the consequent readjustment of the interpreter to goals that are set during the investigation and which impose continuous changes in his/her working strategy.

We will present some introspective considerations which result from the analysis of the interpreter's role during wiretapped conversations. Starting from our professional experience, the goals of this study are: identifying the interpreting procedures applied during wiretapped conversations, analysing the extra- and intra-contextual elements of this communicative situation, examining the parties involved, their tasks and functions and, finally, suggesting some methodological recommendations meant to assist interpreters involved in this difficult task.

KEY WORDS Interpreting in legal settings, Interpreting for wiretapped conversations, Dialogue Interpreting, Telephone Interpreting 


\section{PREÁMBULO}

El presente trabajo forma parte de un proyecto de estudios dedicado a la interpretación en/para escuchas telefónicas en ámbito judicial, concebido a partir de un análisis auto-perceptivo de dos encargos de interpretación para escuchas telefónicas realizados en Italia por la autora de estas páginas. Esta experiencia profesional engarzaba a la perfección con las dos líneas de investigación emprendidas; la primera, centrada en el estudio de la interpretación telefónica — con análisis metodológico de su ejercicio profesional y su aplicación en formación y didáctica de esta específica modalidad de interpretación - y una segunda línea de estudios que indaga sobre formas de mediación aplicadas a la metodología de trabajo operativa en interpretación judicial —ésta última, como continuación de la labor iniciada con el grupo de investigación internacional ImPLI concluido en septiembre de 20I2. ${ }^{\text {I }}$

El proyecto de estudios sobre interpretación para escuchas telefónicas fue presentado en el congreso internacional Interpreter-mediated interactions: methodologies and models (Roma, 20I3). A partir de esta presentación, se ha realizado un trabajo en el que se reflexiona sobre la aplicación de parámetros de mediación en el trabajo del intérprete de escuchas (González Rodríguez, 20I4a), además de otro estudio sobre las características que analiza la interpretación de escuchas como forma de interpretación telefónica (González Rodríguez, en prensa). En esta ocasión, se propone un examen descriptivo del trabajo del intérprete de escuchas y su meto-

I ImPLI -Improving Police and Legal Interpreeting-, dentro del marco SIGTIPS - Special Interest Group on Traslation and Interpreting in Public Services. En González Rodríguez (20I4b) se presenta brevemente este proyecto de investigación. Para mayor información: http://eulita.eu/ sites/default/files/traducci\% $\mathrm{C}_{3} \%_{3} \mathrm{~B}_{3} \%_{2} 0 \%_{2} \mathrm{OImPLI} \%_{2} \mathrm{O}$ versi $\%_{3} \mathrm{C}_{3} \mathrm{~B}_{3} \%_{2}$ ofinal\%20(I).pdf

dología operacional, así como una catalogación disciplinar de esta modalidad de interpretación. Queda reservada para la segunda parte de este proyecto un análisis de las dificultades genéricas de la interpretación de escuchas telefónicas (IET) y un trabajo dedicado a propuestas de formación y didáctica de la misma, a partir de los resultados recogidos en un seminario sobre IET para operadores del sector judicial, impartido por la autora a petición del Cuerpo de Traductores de la Universidad Nacional de Rosario (Argentina).

\section{PREMISAS E INTRODUCCIÓN}

Antes de adentrarnos en el análisis del objeto de este estudio - intervención o interceptación telefónica y su interpretación- cabe señalar algunos aspectos contextuales que pueden resultar útiles para enmarcar y ubicar la labor del intérprete de escuchas telefónicas. Desde un punto de vista social, las escuchas telefónicas (ET) se han convertido en un tema de gran actualidad; el conocimiento de su existencia ha ido cobrando cuerpo en las últimas décadas y en tiempos recientes se ha tomado conciencia de la frecuencia e intensidad de su práctica. Por otra parte, la figura del intérprete en ET ha salido a relucir a través de cuestiones de gran impacto social, como el terrorismo internacional o el crimen organizado — narcotráfico, tráfico ilegal de armas, trata de personas, etc.- - fenómenos todos ellos altamente globalizados, causando así una constante preocupación en la comunidad internacional, afanada perennemente en buscar mecanismos y/o crear estructuras de colaboración entre los Estados miembros para frenar o prevenir numerosas actividades criminales. Por otro lado, hay que subrayar que el desarrollo de las nuevas tecnologías ha permitido que las escuchas telefónicas hayan experimentado una 
neta mejora en la calidad de las mismas, pero sobre todo, ha provocado una suerte de 'ampliación' tanto de las modalidades como del uso de las mismas, incluidas las intervenciones telefónicas utilizadas en espionaje empresarial, o por encargo a agencias privadas de investigación — casos de adulterio, por ejemplo_-, actividades que pueden resultar no del todo conformes a la ley o no responder 'in toto' a la mayor parte de los marcos jurídicos reguladores, como por ejemplo los de nuestro entorno, la Unión Europea (UE). Además, y siempre como consecuencia precisamente de la evolución de las tecnologías de la información y la comunicación (TIC), no hay que olvidar que la Justicia se está viendo obligada a una constante revisión de la legislación emanada al respecto para poder afrontar la incesante innovación tecnológica - nuevos soportes, nuevos medios, nuevas formas de comunicación e incluso nuevos delitos-.

La existencia de escuchas telefónicas, desde un punto de vista conceptual, la podemos imaginar desde el nacimiento mismo de esta tipología de comunicación, colocándola dentro de la familia de las interceptaciones de las comunicaciones - junto a otras, como la postal por ejemplo-, por lo que la idea o el significado de 'intervención’ o ‘interceptación’ telefónica es plausible suponerla desde tiempos muy remotos.

Desde la perspectiva de la Justicia, cabe indicar que las interceptaciones inciden profundamente en la delicada cuestión del derecho a la inviolabilidad de las comunicaciones. La necesidad de legislar en materia no es reciente, encontrando ya claros antecedentes en la Revolución francesa, que proclama en I79o la inviolabilidad de la libertad y el secreto de las correspondencias (López Fragoso, r99r: I3); se trata de uno de los Derechos Fundamentales, recogido en el art. I2 de la Declaración de los Derechos Humanos, o en el art. 8 del Convenio Europeo para la Protección de los Derechos Humanos y las Libertades Fundamentales (Marco Urgell, 20Io: 15-24). Visto lo expuesto, no es difícil entender el enorme volumen de literatura jurídica que se ha dedicado y se dedica aún a este argumento, y los motivos por los que, actualmente, se registra un intenso y delicado debate sobre el tema en el ámbito de la Justicia. En cualquier caso, llama la atención el calado reconocido y reconocible de las interceptaciones o intervenciones como instrumento judicial, y a su vez, la escasa presencia de la figura del intérprete en la legislación pertinente. ${ }^{2}$ Más aún sorprende que una actividad tan compleja como la del intérprete de ET, y de tan suma importancia para el engranaje de los procesos y procedimientos judiciales, no se le haya concedido hasta el momento el debido espacio de estudio, de reflexión o de análisis en la literatura científica de la disciplina de la interpretación, salvo dignas excepciones, como Olalla (2006), Handi y Ortigosa (20II) u Ortega Herráez (20II).

\section{DEFINICIÓN DE ESCUCHAS TELEFÓNICAS}

Sin entrar en detalles, y por los motivos referidos someramente en los puntos anteriores a estas líneas, resulta precavido afirmar que hoy en día la definición jurídica de las interceptaciones o intervenciones telefónicas es un asunto en plena evolución, aunque, indudablemente, encontramos ejemplos en las distintas legislaciones vigentes, nacionales y supranacionales, como la Unión Europea en nuestro caso, que

2 La figura del traductor-intérprete jurado y el derecho a la asistencia de intérprete en procesos judiciales está perfectamente regulado tanto por la legislación española como a nivel internacional, aunque siempre hay puntos de posible ambigüedad y mecanismos que han de revisarse, a tenor de los expertos en materia y de traductores e intérpretes que trabajan para/con la Justicia y/o fuerzas de seguridad del Estado. 
disciplinan la materia, quedando perfectamente perfilada para las exigencias de este estudio.

Por lo que respecta a España, el derecho a 112 la inviolabilidad de las comunicaciones está recogido en el art. I8 de la Constitución de 1978, con antecedentes en el art. 7 de la Carta Magna de 1869, y el art. 32 de la Constitución de 193I (Marco Urgell, 20Io: 9-14); en el art. I8.3 es posible interpretar una referencia a las interceptaciones de las comunicaciones, ya que a partir del mencionado artículo se plantean distintos grados de posible vulneración del secreto. ${ }^{3}$ En cualquier caso, la intervención de las comunicaciones en España está disciplinada por el art. 579 y siguientes de la Ley de Enjuiciamiento Criminal vigente. ${ }^{4}$ En Italia, donde han tenido lugar los dos encargos de interpretación para escuchas telefónicas protagonistas de este estudio, la inviolabilidad de las comunicaciones queda recogida en el art.I5 de su Carta Magna; también ella, y por imperativo constitucional, expresa que la interceptación telefónica sólo puede ser ordenada por autoridad judicial en la fase de la investigación preliminar, existiendo indicios graves de culpabilidad, cuya regulación queda recogida en los arts. 266 y siguientes del Código Procesal Penal italiano. ${ }^{5}$

Una vez construido el marco legislativo del objeto de nuestro estudio, se adjuntan dos de las numerosas definiciones que podemos encontrar, todas ellas muy similares; A este respecto, Obón Díaz (2004:307) escribe:

3 En el portal del Congreso de España es consultable el texto completo de la Constitución: http://www.congreso. es/consti/constitucion/indice/.

4 La Ley de Enjuiciamiento Criminal, con reforma de 20I2, es consultable en: http://noticias.juridicas.com/ base_datos/Penal/lecr.html.

5 Capítulo IV, Interceptaciones de conversaciones o comunicaciones (art. 266 al 27I). Para consultas del CPP italiano: http://www.altalex.com/index.php? idnot $=36787$, equivalente a la Ley de Enjuiciamiento Criminal en España.
Utilizando palabras del propio Tribunal Supremo puede entenderse como intervención telefónica «Unas medidas instrumentales que suponen una restricción del derecho fundamental del secreto de las comunicaciones y que aparecen ordenadas por el Juez de Instrucción en la fase instructora o sumarial del procedimiento penal, bien frente al imputado, bien frente a otros con los cuales éste se comunique, con la finalidad de captar el contenido de las conversaciones para la investigación de concretos delitos y para la aportación en su caso, de determinados elementos probatorios».

Por su parte, López Fragoso define las intervenciones telefónicas (apud Marco Urgall, op. cit., p. 68) especificando textualmente una cuestión de gran relevancia para los quehaceres de los intérpretes de escuchas, que subrayamos en la siguiente cita:

[...] aquellas medidas instrumentales restrictivas del derecho fundamental al secreto de las comunicaciones privadas, ordenadas y ejecutadas en la fase instructoria de un proceso penal bajo la autoridad del órgano jurisdiccional competente frente a un imputado $-\mathrm{u}$ otros sujetos de los que éste se sirva para comunicarse- con el fin de, a través de la captación de lo comunicado o de otros aspectos del proceso de comunicación, investigar determinados delitos, averiguar el delincuente $y$, en su caso, aportar al juicio oral determinados elementos probatorios.

Cuando especifica 'lo comunicado' y 'otros aspectos del proceso de la comunicación' está haciendo clara referencia a la tridimensionalidad de la comunicación, en la que converge no sólo el mensaje verbal —entendido como código lingüístico-, sino también el mensaje paralingüístico y los gestos comunicativos, un asunto complejo y decisivo en la interpretación de escuchas, del que nos ocuparemos más delante.

En definitiva, las intervenciones telefónicas se consideran un medio instrumental para investigar la posible comisión de un delito y 
a su/s presunto/s autor/es y colaborador/es, pudiendo además ser utilizadas, en su caso, como medio probatorio - es decir, presentan un valor dual por ser fuente de investigación y, a su vez, fuente de pruebas, si queda garantizado el respeto a las leyes procesales. Como se apuntaba al principio de este apartado, la norma jurídica se ve abocada hoy más que nunca a continuas revisiones que le permitan evolucionar en consonancia con el avance tecnológico y compatibilizarse en lo posible con la jurisprudencia internacional.

\section{INTERPRETAR PARA ESCUCHAS TELEFÓNICAS: DESCRIPCIÓN OPERATIVA Y DEFINICIÓN DISCIPLINAR}

El trabajo del intérprete de escuchas ha de catalogarse dentro de la interpretación en ámbito judicial, y más específicamente, de la interpretación policial. En este tipo de entorno se suelen dar situaciones comunicativas fundamentalmente dialógicas - y, por lo tanto, tríadicas-, como por ejemplo interrogatorios, audiencias, declaraciones, entrevistas con los abogados, etc., aunque también es conveniente señalar la tendencia existente en los últimos años a integrar en los mecanismos de la Justicia servicios de interpretación a distancia (interpretación telefónica o interpretación de videoconferencias) por motivos justificados, un tema sin duda interesante, de gran actualidad y relacionado con la interpretación de escuchas (a partir de aquí, IET), pero que, por motivos de espacio, queda aplazado para otra ocasión.

Como se apuntaba anteriormente, en las últimas décadas la figura del intérprete de ET ha ganado un cierto prestigio social; el imaginario colectivo le ha otorgado un perfil un tanto cinematográfico, en el que se visualiza al intérprete trabajando en soledad con aparatos telefónicos, pero en realidad no es así. En una IET se realiza una operación de transferencia de información y/o contenidos comunicados desde la parte telefónica a una parte presencial, con cambio de código lingüístico incluido. En ese sentido, nos encontramos ante una acción tríadica y dialógica, condición prototípica de una interpretación bilateral, perfectamente descrita por Collados Aís y Fernández Sánchez (200I), con elementos caracterizadores como el contacto directo en espacio compartido (presencialidad), la diversidad de contextos y situaciones conversacionales, la imprevisibilidad, la diversidad temática, la presencia de automatismos conversacionales y 'actos de habla', la variedad de estilos y registros, o la toma de notas, acompañado todo ello de su correspondiente base teórica y cuadro metodológico (200I: 6I-94); además, por encontrarnos en ámbito de interpretación judicial/policial - por lo tanto, en servicios públicos-, se verificarán situaciones comunicativas asimétricas bastante marcadas - diferencias culturales y diferencias de roles entre las partes implicadas- y el factor clave de una interpretación bilateral (IB), la bidireccionalidad, también estará presente, aunque de forma particular.

Cuando mencionamos la IB nos referimos a una disciplina en su significado estricto, ${ }^{6}$ generadora de cuadros metodológicos capaces de dar respuesta a las numerosas dificultades multifactoriales propias de la IB,7 especialmente

6 Se entiende por «disciplina» la suma de teorías y conocimientos propios de una profesión, plasmada en un aparato metodológico, o lo que es lo mismo, en un conjunto de reglas comportamentales que nos permite sistematizar nuestra operatividad en el ejercicio profesional (González Rodríguez, 2014a: 207).

7 En ocasiones anteriores hemos reflexionado sobre ella y la hemos descrito en distintos trabajos desde varios puntos de vista: desde la formación (González Rodríguez $2006 a, 2006 b$ ), desde su ejercicio profesional para cubrir las necesidades de los SSPP (20IO, 2OII), o como posible recorrido de especialización $\left(20 \mathrm{I}_{4} b\right)$. 
en ámbito de servicios públicos (SSPP), como es el caso de la IET. En la labor del intérprete de escuchas se consiguen identificar todos y 114 cada uno de los elementos caracterizadores de la IB presencial (o si se prefiere, interpretación dialógica), por lo que podemos ya afirmar que operamos con esta disciplina metodológica en el trabajo que realizamos con y para los funcionarios implicados en la investigación objeto de una IET.

Sin embargo, la 'naturaleza genética' de la IET es intrínsecamente telefónica. Por esta razón esta tipología de interpretación es también catalogable como una interpretación telefónica (IT), y de hecho, en una operación de IET se reconocen perfectamente las principales características de la IT, como la particularidad de trabajar, con la parte que está al otro lado del teléfono, en 'modalidad percepción monosensorial', diligenciar una 'multidiversidad acelerada', gestionar situaciones comunicativas fuertemente asimétricas, y operar con 'grado de tensión cero':

- Percepción monosensorial: se trabaja en una situación 'a ciegas', teniendo como único input comunicativo el audio telefónico. La condición de 'no ver' del intérprete no tiene que ser necesariamente compartida por las partes a las que asiste; en una 'llamada a tres' las estrategias de trabajo cambian respecto a una tradicional llamada 'cara a cara' ${ }^{8}$

- 'Multidiversidad acelerada': se debe entender que el intérprete de IT, por la modalidad de

8 Un ejemplo de 'llamada a tres': el intérprete al teléfono atiende a un policía en Comisaría y a un turista que desde la recepción de su hotel denuncia que ha sido víctima de un robo; en este caso ninguna de las tres partes comparte espacio. Por el contrario, en una llamada 'cara a cara' las partes asistidas por el intérprete sí que comparten espacio (denunciante y policía en Comisaría, y el intérprete al teléfono, por ejemplo).

servicio y las exigencias que comporta, ha de atender multitud de temas, de situaciones comunicativas, de contextos, de usuarios, etc., y sus tiempos de reacción y 'colocación' en situación deben ser muy breves. ${ }^{9}$

- Asimetría marcada: es plausible imaginar situaciones de fragilidad de una de las partes (accidente, robo, pelea en la escuela, etc.) con diferencias de roles importantes (policíal detenido, paramédico/accidentado, etc.).

- Tensión de 'grado cero': en una IT el intérprete debe estar preparado para cualquier cosa ${ }^{\text {Io }}$ desde un banal trámite burocrático a un accidente de tráfico grave, un caso de violencia de género, llamadas de servicios de urgencias de hospitales, etc. Esta cuestión genera de por sí una tensión constante a la que hay que acostumbrarse y saber gestionar (tensión 'grado cero'); en los casos de llamadas de servicios de emergencias, el intérprete debe reaccionar en pocos segundos para contextualizar e identificar estrategias de trabajo en situaciones de gran dificultad comunicativa - por factores emocionales, por ejemplo-, y en ocasiones, el intérprete de IT ha de adaptarse, a veces, a situaciones de alta tensión entre las partes. ${ }^{\text {II }}$

No hay que dejar de precisar que, además

9 Comisarías, hospitales, escuelas, para rellenar un formulario, para llamar una ambulancia, para hablar con los padres de un alumno, para cita médica programada, para seguimiento de un paciente con movilidad reducida, para tramitar un documento de identidad, permisos de residencia, etc.

ı Normalmente el intérprete desconoce lo que le espera al otro lado del teléfono: cuando acepta la llamada, habla directamente con las partes implicadas, y los clientes (médico, maestra, policía) le referirán el motivo de la llamada.

II Diferenciamos entre tensión 'grado cero', generada por el propio intérprete en esta modalidad de trabajo, y la tensión heredada por los contextos y situaciones asistidas que afectan de forma importante al intérprete que asiste. 
de los puntos brevemente desarrollados, la IT desde un punto de vista metodológico sigue siendo una interpretación bilateral, aunque practicada en condiciones particulares; para afrontar este tipo de trabajo se requiere contar con una sólida preparación y experiencia como intérprete bilateral, ya que la ausencia de determinados factores (presencialidad, por ejemplo) se deberá compensar con una explotación máxima de los recursos disponibles (como la voz y su información paralingüística) así como la habilidad y rapidez en identificar situaciones y contextos comunicativos para activar rápidamente estrategias. ${ }^{12}$

En resumen, podemos afirmar que la descripción operativa de una IET abarca todo lo expuesto, y no solo. Por una parte estamos operando con una IB, pero siempre conjugada con una IT. La interpretación de escuchas telefónicas es una modalidad híbrida compuesta por todos los ingredientes mencionados, aderezados además con una serie de circunstancias y necesidades muy particulares que pasamos a desarrollar en el siguiente punto.

\section{CONDICIONES CARACTERIZADORAS DE LA INTERPRETACIÓN PARA ESCUCHAS TELEFÓNICAS (IET)}

La interpretación para/en intervenciones telefónicas no es la suma de una interpretación bilateral y una interpretación telefónica. En realidad, estamos ante una peculiar fusión de ambas, una especie de coexistencia, se complementan en simbiosis, y será el intérprete de ET el que deberá orquestar las relaciones entre estas dos modalidades de interpretación.

I2 La IT presentada y ejemplificada en este trabajo va dirigida a servicios públicos, dejando a un lado la IT empresarial, turística o dirigida a servicios de asistencia a privados en el extranjero, por ejemplo.
La peculiaridad reside en muchos de los elementos que la caracterizan, pero sobre todo en el objeto con/por el que trabaja, la interceptación. Efectivamente, no es habitual para la gran mayoría de los intérpretes trabajar con $\mathrm{ET}$, aunque sí es cierto que con la experiencia de un encargo de este tipo el intérprete no sólo puede imaginar la intensidad y la frecuencia de las intervenciones referidas al principio de estas páginas, sino sobre todo el alcance y la magnitud que encierran las labores de interpretación para investigaciones policiales y procesos judiciales.

Comenzaremos por analizar los efectos que conlleva para un intérprete empezar a trabajar con escuchas telefónicas; como toda primera experiencia, el primer encargo de una IET puede parecer sorprendente y curioso al principio, pero también puede abrumar y 'descolocar' al intérprete. La IET resulta abrumadora no sólo por la toma de conciencia de responsabilidades adquiridas — siendo éste un asunto que saldrá a relucir en apartados sucesivos-, sino también por la complejidad de este tipo de trabajo, una cuestión que el intérprete puede percibir ya en sus primeros pasos; y estas primeras sensaciones se avivarán aún más cuando éste llegue a entender que deberá ampararse únicamente en su recorrido formativo, su propia experiencia y su solidez profesional, recursos todos ellos que han debido ser adquiridos antes de afrontar una IET. Respecto a la complejidad metodológica y las responsabilidades adquiridas, para todo intérprete que comienza con una ET sería recomendable recibir formación específica para esta tipología de trabajo, pero lamentablemente, ni existen cursos reglados, ni seminarios específicos sobre metodología de la IET, ni en el encargo de IET se recibe preparación inicial al respecto ${ }^{\mathrm{r} 3}$-aunque casi siempre es posible

I3 Cuando se apunta 'preparación inicial para una IET' 
contar con la disponibilidad e inestimable colaboración de los agentes implicados en las tareas de escuchas. Por su parte, la 'descolocación' mencionada del intérprete obedece a dos factores; el primero tiene que ver con las condiciones de recepción del audio: es cierto que las grabaciones de las ET son cada vez de mejor calidad, pero en interpretación se acostumbra - y se exige como condición indispensable de trabajo- que el audio sea 'limpio', nítido, sin ruidos y aislado, mientras que en una ET el intérprete se va a encontrar con un audio inconcebiblemente 'sucio' para los menesteres de interpretación, lleno de ruidos, voces que se sobreponen, caídas de línea, cobertura intermitente, etc. El segundo factor se relaciona con la gestión de la interacción al otro lado del auricular; la habitual 'colocación' del intérprete respecto a la situación comunicativa en la que trabaja puede ser varia$\mathrm{da}$, e incluso variable en una misma operación de IB, pero una cosa es cierta: el intérprete está 'en' la situación comunicativa, incluso en las modalidades de interpretación remota. E1 intérprete 'está' y gestiona, orquesta, orienta, organiza y lleva adelante la situación comunicativa. En el caso de escuchas, el intérprete ha de trabajar con una situación comunicativa en la que 'no está, que no le pertenece, que no gestiona, que no controla, que no orquesta, algo absolutamente innatural, o incluso antinatural para un profesional de la interpretación. Para afrontar una situación de este tipo, el intérprete de ET deberá cimentar su trabajo en la llamada 'escucha activa', e invertir gran parte de sus energías en explotar esta habilidad al máximo de sus posibilidades, ya que todo — su trabajo, y la propia investigación - parte de ahí.

La escucha activa es siempre indispensable

se hace referencia a preparación principalmente metodológica; un curso de iniciación práctica impartido por un intérprete consolidado en IET sería lo ideal en estos casos.

en una interpretación, sea cual sea su naturaleza, de ella depende prácticamente todo y sin ella es imposible interpretar; esta habilidad nos permite comprender, y acto seguido estructurar, memorizar, etc., hasta llegar al momento de la reformulación y 'transferencia' de lo comunicado por la parte emisora a la parte receptora. En el caso de una IET, si bien es cierto que existen numerosas dificultades respecto a las interacciones telefónicas que se intervienen y que se han de interpretar, también es verdad que contamos con la gran ventaja de trabajar con grabaciones; lo habitual es que en una ET se interpreten para la parte presente las conversaciones anteriormente grabadas, aunque también es posible entrar 'en línea', es decir, interpretar una llamada que entra en ese instante y que, por motivos varios y múltiples, se decide atender esa interceptación y abandonar momentáneamente el trabajo con grabaciones, una cuestión peculiar que reservamos para el apartado dedicado a la descripción de un encargo de IET. Por lo tanto, se puede afirmar que trabajar con grabaciones ayuda al intérprete a maximizar las operaciones de 'escucha activa' - frases intercaladas, superposición de input varios, velocidad de discurso, problemas de cobertura, etc. - - lo que no significa que se resuelvan así todas las dificultades que encuentra el intérprete operando con la parte telefónica.

Antes de pasar a describir el trabajo que se realiza con la parte presencial - agente/s, funcionario/s - es necesario subrayar algunos aspectos del trabajo del intérprete con 'las voces'. Además de las circunstancias anteriormente indicadas, en una ET las voces son protagonistas absolutas hasta el punto que se convierte en sustancial la rapidez con que el intérprete las identifique, se 'familiarice' con 
ellas y las 'conozca' en profundidad. ${ }^{\mathrm{I}}$ Olalla Fernández expone reflexiones muy acertadas en este sentido (2006: 243-246) y recalca la importancia de 'las voces' por ser una cuestión trascendental para la investigación, retratándola como una operación en la que el intérprete encontrará «innumerables escollos» (2006: 243).

Las voces - en una IET siempre hay más de una, y pueden llegar a ser tantas- no podemos 'verlas', por lo que toda la información paralingüística que podamos obtener resulta primordial, ya que las voces no sólo 'dicen', sino que también 'hablan' de sí mismas. El intérprete ha de recabar de ellas el perfil de las personas a las que pertenecen 'esa voces', y para eso ha de estar muy atento a lo que hemos convenido en llamar 'tridimensionalidad' de la comunicación, dada por su componente lingüística, paralingüística y quinésica: a través de la primera podremos identificar, entre otras cosas, rasgos diatópicos, diastráticos y/o diafásicos —información sobre la zona de uso lingüístico, sobre nivel cultural, sobre registro de habla, etc.-, con la segunda es posible indagar incluso sobre reacciones fisiológicas y/o emocionales, - no sólo cuestiones hombre/mujer, anciano/niño, sino también si está sano, enfermo, nervioso, alegre, enfadado, dudoso, asustado, etc. Poyatos (1994) nos asiste en estas operaciones con instrumentos tan válidos como su clasificación de «las cualidades primarias o rasgos personales básicos de la voz» (1994: 25-49), o "calificadores o tipos de voz» $\left(49^{-82}\right)$, y nos orienta incluso en la tercera componente de la tridimensionalidad mencionada, sobre los gestos comportamentales comunicati-

${ }^{14}$ Hay que considerar que, si bien en las intervenciones contamos con número intervenido y propietario/a del mismo, no siempre queda perfectamente claro que es ' $\mathrm{X}$ ' el que está hablando, ya que el teléfono puede intercambiarse, prestarse o usarlo puntualmente otra persona distinta a la habitual. vos con su capítulo «de las coactividades sonoras del lenguaje: de la kinésica [sic] audible a los sonidos ambientales» $\left(235^{-262}\right)$. En definitiva, la comunicación no verbal (CNV) se revela no sólo imprescindible sino que además se puede convertir en 'llave de acceso' a información 'no dicha' pero 'sí comunicada': en una IET este enorme recurso se convierte en eje principal cognitivo para el intérprete, y a través de la CNV podrá entender y transferir el significado último de lo dicho, o no dicho (Poyatos, I998: 47-70) —silencios, ironía, incredulidad, sorpresa, confesión, amenaza, etcétera. En cualquier caso, estas lecturas subliminares, como el resto del trabajo de identificación de los perfiles y la orientación que paulatinamente va tomando la investigación, son fruto de la estrecha colaboración en el trabajo que ha de existir siempre entre el intérprete y la/s parte/s presenciales. No hay que olvidar que la actividad de ET se comparte constantemente con los agentes/funcionarios presentes, por lo que el trabajo del intérprete en escucha no es una labor individual y solitaria, se escucha siempre en compañía, el trabajo de una IET es multilateral, ${ }^{15}$ un trabajo de equipo (Handi y Ortigosa, 20Ir: 23).

Pasemos ahora al trabajo del intérprete de escuchas con la/s parte/s presencial/es, que lo expresamos tanto en singular como en plural por ser precisamente así, variable. En Italia, lugar donde tuvieron lugar los dos encargos de escuchas, las intervenciones telefónicas y el seguimiento de las mismas deben realizarse en el mismo edificio donde se ubica el Tribunal del Juez instructor que ordena las intervenciones

I5 Aunque los agentes no conozcan el idioma en escuchas, su experiencia y habilidades de escucha adquiridas son valiosas, $\mathrm{y}$ hace que estos agentes sean perfectamente capaces de 'oir' sorpresa, estupor, terror, alegría... gestos paralingüísticos y quinésicas que retratan e incluso delatan las intenciones comunicativas. 
de determinada investigación, es decir, el intérprete no puede trabajar desde casa, solo, o en cualquier otro lugar, sino en constante compañía de los agentes/funcionarios en la ubicación referida, donde se encuentran las instalaciones técnicas y el equipamiento para escuchas. Normalmente las investigaciones son un trabajo de equipo, con implicación de varios agentes, sin embargo, si no se trata de una investigación de suma importancia o de extrema gravedad, el encargo se confía a un solo intérprete; esto comporta que este trabaje para/con distintas personas, con cambio de turno o, en momentos cruciales, con varios de ellos a la vez —en una misma jornada el intérprete puede trabajar con uno o varios agentes-, lo que deriva en una serie de adaptaciones ineludibles por parte del intérprete según la persona con la que trabaje.

La información en sí nunca es monolítica, es siempre interpretable y se percibe de forma variada; los contenidos de las escuchas llegan al intérprete y será él quien 'prepare' y 'facilite' dichos contenidos a los agentes, dependiendo siempre de las necesidades/prioridades de estos últimos —en esto puede influir también el momento preciso por el que atraviesa la investigación-. En este aspecto, es imprescindible crear un ambiente de estrecha colaboración para que el trabajo resulte fluido, eficaz, y que la orientación de la investigación sea la correcta, pero como bien sabemos las personas no son todas iguales y las relaciones que se establecen, por ende, son distintas: un agente puede estar más atento a informaciones de tipo paralingüístico, mientras que otro prefiere la información rápida y sin matices, o un agente establece una colaboración relajada con el intérprete y, por el contrario, otro se siente más cómodo tratando de usted al intérprete, con modos muy formales.

Sobre la cuestión relacional entre las partes implicadas en una IET se ha reflexionado en trabajos anteriores (González Rodríguez, 2oI4a) y se ha propuesto un cuadro operativo multidisciplinar — sociología, psicología y antropología- con bases metodológicas provenientes del ámbito de la mediación intercultural. En estas líneas es indispensable subrayar la importancia de las relaciones entre las partes de una IET y la obligada atención que el intérprete debe prestar a este aspecto; las relaciones a las que hacemos referencia no son sólo las surgidas en sala de ET con los agentes presentes, o las existentes entre 'las voces', sino también las surgidas/creadas por el intérprete con 'las voces', las personas escuchadas, e incluso las que se establecen entre los agentes y dichas voces. Estamos hablando de un entramado relacional complejo que el intérprete ha de analizar detenidamente para conocerlo y poder gestionarlo, y esto es así por una sencilla razón: esas relaciones influyen en las situaciones comunicativas que se establezcan, en las intenciones comunicativas y sus posibles interpretaciones; para entender mejor por qué $\mathrm{X}$ cuando habla con Y lo hace con sumisión, o con pudor, o con agresividad, es necesario que el intérprete identifique la relación existente entre $\mathrm{X}$ e Y, lo cual puede parecer banal, pero no lo es tanto si consideramos que no existe un momento de presentación y aclaración de quién es quién entre el intérprete y las partes al otro lado del teléfono. Las relaciones de las personas intervenidas hay que descubrirlas, y no es tarea fácil o inmediata cuando estamos en un ambiente de actividades criminales. De igual forma, como se apuntaba antes, hay que prestar atención a la relación que, cultural o sociológicamente, establece el agente A o el agente B o el mismo intérprete, con las personas en escuchas - tintes despectivos, o empatías, o rechazos, etcétera. A tenor de lo expuesto, cabe afirmar que el aspecto relacional, desde el momento en que entendemos que se crea y se establece ineludiblemente 
por nuestra 'naturaleza social', determina el trabajo del intérprete y la labor de los agentes, por lo que es absolutamente prioritario considerarlo como un elemento más que se habrá de gestionar en IET.

Por último, no es posible concluir este apartado sobre elementos y condiciones caracterizadores de una IET sin mencionar dos factores que suelen ser determinantes en interpretación: el espacio y el tiempo. Respecto al primero se ha reflexionado sobre la presencialidad y su ausencia (IB/IT), pero aún no se ha considerado el espacio existente al otro lado del teléfono: es información absolutamente prioritaria en una IET, y cualquier referencia al mismo - dirección, lugar de encuentro, de intercambio - va atentamente indicada por el intérprete. A veces, la 'no información' sobre un lugar cobra importancia como posible punto de inflexión de la investigación: «nos vemos en la esquina donde empieza el mercadillo» ${ }^{16}$ es una información que hay que desgranar, porque dependiendo del día de la semana y de la localidad a la que hacen referencia en esa llamada podemos imaginar virtualmente el lugar del encuentro, es decir, que el espacio en una IET, su interpretación y las posibles referencias al mismo no siempre son inmediatas y explícitas, por lo que el espacio, tantas veces, es una información 'construida' virtualmente por el intérprete con los agentes. El tiempo, por su parte, es un elemento que se 're-construye' también en colaboración: «hace dos días» pueden ser más de dos, depende del día en que fue grabada la conversación, por no hablar de «ayer a mediodía» o «mañana por la tarde», conceptos marcadamente culturales, que pueden cambiar de un código lingüístico a otro, y que han de calibrarse bien cuando el agente de

I6 Se trata de un simple ejemplo que no obedece a situaciones reales vividas en encargo de IET. turno pide una especificación, indicar una franja horaria, etc. Además, el tiempo, entendido como horario de trabajo en un encargo de IET, llega a convertirse en un elemento que puede generar tensión al intérprete, ya que cuando da su disponibilidad para una IET lo debe hacer sin horarios fijos, de lunes a domingo, y a sabiendas de cuándo empieza el trabajo, pero sin certeza alguna de cuánto va a durar dicho encargo —es siempre una incógnita si se va a complicar un seguimiento de escuchas o si cambiará la orientación del caso.

En resumen, podemos considerar la IET como un complejo escenario donde se denota claramente que el trabajo del intérprete de ET va mucho más allá de lo puramente lingüístico, de 'lo comunicado' sino más bien 'lo dicho, o no dicho, con sus intenciones comunicativas', debidamente situadas y contextualizadas, fruto de un análisis tridimensional de la comunicación y de una reflexión interrelacional, que sopesa continuamente aspectos intra e interculturales de la comunicación dada. Como afirmábamos al principio de estas páginas, se trata de una labor complicada, de gran responsabilidad, generadora de efectos colaterales en el intérprete y, sin embargo, poco reglada y menos reconocida, hasta ahora, aunque estas circunstancias deberán cambiar, por efecto de la directiva 64/2010 del Parlamento Europeo y del Consejo Europeo, punto que trataremos más adelante.

\section{UN ENCARGO DE IET: OPERACIONES IMPLICADAS}

En el presente apartado se exponen brevemente los mecanismos y procedimientos vividos como experiencia personal en la asignación de encargos de IET. Dicho recorrido obedece a la legislación vigente en el año en que tuvieron lugar dichos encargos (2012), aunque conviene 
subrayar que tal normativa se verá modificada por la directiva anteriormente mencionada en algunos de sus términos (directiva 64/2010 UE, con indefectible entrada en vigor en los Estados Miembros antes del 27 de octubre de 2013).

Todo empieza cuando el juez instructor considera que existe un grave indicio de delito y expresa la absoluta necesidad de ordenar la/s intervención/es telefónica/s para la prosecución de las investigaciones, dando lugar así al decreto de las operaciones de intervención/ interceptación, en las que, en el caso de presencia de lenguas extranjeras, intervendrá la figura del intérprete. ${ }^{\mathrm{I} 7}$ Sin entrar en el relato de los procedimientos tipificados en la Ley de enjuiciamiento criminal italiana (Codice di Procedura Penale), apuntaremos que no existe un sistema de selección específica de intérpretes y/o verificación previa de las competencias necesarias para tal encargo, sino que los mismos oficiales/ inspectores implicados en la investigación en la que se han decretado las ET, y basándose en su vasta experiencia profesional, serán los que entrevisten al candidato -indicado frecuentemente como apto por colaboraciones anteriores en ámbito judicial_-, estudien su preparación y decidan si asignarle el encargo o no. En este sentido, y en honor a la verdad, los responsables de la selección del intérprete demostraron gran seriedad, profesionalidad, prestando también un especial interés en aclarar algunos de los aspectos caracterizadores del trabajo de una IET. $^{\text {.8 }}$

${ }_{17}$ Resumen de lo disciplinado en el C. P. P. italiano (LeCRIM) art. 267, apartados I, 3 y 5.

I8 Tiempos, medios, ubicación, presentación de al menos uno de los agentes implicados y breves apuntes sobre la naturaleza del caso; incluso suelen pedir disculpas de antemano por la ínfima remuneración y poco reconocimiento que el sistema de la Justicia otorga a la figura del intérprete en ámbito judicial y policial. Sobre la remuneración: va calculada por unidades de 2 horas, llamadas «vacazioni», que no pueden exceder de 4 al día (serían ya ocho horas de interpretación en una sola jornada); los honorarios de

El intérprete que afronta por primera vez un encargo de ET debe 'aprender' todo en su primer día laboral, por lo que el funcionario/agente que le acompaña en esa jornada resulta determinante: ésta será la persona que introduce al intérprete en la investigación en curso, los teléfonos intervenidos, las personas implicadas, motivando las causas e informándole sobre el punto de la situación en la que se encuentra la investigación judicial y lo recabado hasta el momento con las ET.Además, es él quien se encargará de mostrar al intérprete los instrumentos informáticos y tecnológicos con los que se trabaja, — siempre en compañía de un agente, o varios de ellos- y lo más importante aún: le aproxima a las dinámicas de trabajo habituales, como la escucha dual simultánea — agente e intérprete — de las grabaciones, con un seguimiento muy intenso al inicio de esta colaboración para 'presentar' al intérprete las voces que hasta el momento se encontrará en grabación, y la explicación de los métodos de trabajo y tareas que se requieren del intérprete: breve resumen descriptivo de la llamada al inicio de cada una de las mismas - turno de IB con pausa de escucha o con técnica de susurrado- y continuar con la escucha en común, durante la cual el agente solicita al intérprete detalles o informaciones que podrían resultar relevantes, por lo que convendrá que el intérprete active también la toma de notas para asegurar la estructuración correcta de la interacción en escucha. Dependiendo del resultado de

la primera unidad llegan a I4,68 $€$ brutos (art. I, párrafo I D. M. Justicia 30/5/2002), y por las sucesivas «vacazioni» se abonarán $8,15 €$ brutos. Queda previsto un posible aumento de hasta un $20 \%$ de los honorarios si el magistrado declara la urgencia del servicio con decreto en el que se expresan las motivaciones (art. 5I DPR II5/O2), o duplicar los honorarios si se tratase de una pericia excepcionalmente compleja o de extrema importancia (art. 52 DPR II5/O2). Para mayor información al respecto: http://www.procuravenezia.it $/$ modules/informazioni/index.php?id=33 [consultado I3/12/20I3]. 
estas operaciones preliminares, el agente decidirá si considerar la llamada relevante o no: en el segundo caso, la llamada escuchada pasará a registrarse con su grabación correspondiente en lengua original (LO) acompañada de un resumen o 'traducción resumida' en lengua italiana de los contenidos de la llamada en cuestión, mientras que, en el caso de juzgarla relevante, la llamada será registrada con una traducción integral lo más detallada posible - la denominada por los agentes traduzione letterale o trascrizione, en la que incluiremos información paralingüística y quinésica-. ${ }^{19}$ En cualquier caso, se registran traducciones y grabaciones, ya que la transcripción de las conversaciones en LO se realizan sólo a petición del juez instructor en un momento sucesivo, contratando un transcriptor para ese menester. ${ }^{20}$

Una vez superado el momento de 'inmersión' laboral —con el inestimable y determinante auxilio de un agente experto, pero sobre todo disponible y colaborador- el trabajo del intérprete seguirá el curso de las investigaciones, ya que el intérprete, como se ha visto en estas

I9 $\mathrm{Y}$ es aquí donde el trabajo del intérprete con la comunicación no verbal (CNV) alcanza mayor dificultad, ya que se le solicitará incluir en el texto traducido silencios, posibles 'dobles sentidos', ironías, risas, llantos, pausas, sorpresas, gritos, susurros, etc., presentes en la interacción en lengua original (LO). Los términos utilizados por los agentes no son del todo correctos dentro de nuestro ambiente profesional, y el uso de la palabra 'trascripción' - lejano de lo que en interpretación entendemos por tal- deriva de la necesidad de los agentes de marcar la cuestión de que debe ser una traducción no sólo lo más exacta posible, o fiel, sino que además debe incluir todo el aparato tridimensional de la comunicación. En este caso, una explotación correcta de los signos de puntuación, de los espacios o del uso de mayúsculas/minúsculas pueden ayudar al intérprete en esta tarea nada fácil, en la que se verá obligado a usar numerosas notas entre paréntesis.

20 La sentencia de la Corte di Cassazione del 24/02/20II establece que las labores de transcripción en LO debe realizarlas una persona distinta a la del encargo de IET. líneas, seguirá haciendo su trabajo, interpretar, aunque de forma peculiar: a veces aclara, explica, transfiere, pero también re-construye y selecciona contenidos, tomando tales decisiones 'en equipo'; también es cierto que las investigaciones seguirán la senda 'marcada' por el intérprete, por lo que podemos imaginar los serios daños que un mal intérprete puede causar en una IET. Su trabajo seguirá adelante hasta que salgan a relucir los delitos y se obtengan pruebas sobre los sospechosos de cometer actos criminales. Mientras tanto, el intérprete trabajará sin horario fijo, en días festivos, o cuando se solicita urgentemente su presencia por entrada de una llamada, aparente o supuestamente importante para la investigación - por ejemplo, cuando por fin hablan dos personas directamente tras haber contactado hasta entonces a través de sus representantes, o cuando entra en línea una 'voz nueva' de una persona relevante, o cuando surgen contactos inesperados que puedan dar un vuelco a la investigación o sea indicio para una investigación paralela o tantas otras circunstancias-. Cuando la investigación se va acercando a una determinada conclusión, el intérprete se ha de preparar para momentos de gran tensión, en los que puede aparecer la tan esperada llamada, en línea directa o grabada. En estos casos es probable que en la misma sala de interceptaciones se encuentren no sólo intérprete y agente, sino también comisario/s y varios agentes, todos a la espera de lo que pueda decir el intérprete, para salir rápidamente y activar dispositivos para posibles arrestos; un momento, sin duda alguna, de gran tensión general, especialmente para el intérprete, por la responsabilidad que conllevan sus palabras en aquel preciso instante.

Hasta ahora se ha sacado a colación las llamadas grabadas o la llamada en línea directa, pero el intérprete trabajará también con chats, fórums, sms, con skype, con facebook, y todos 
los demás canales de comunicación posibles desde un teléfono móvil. En una IET se utilizarán distintas modalidades y técnicas de interpretación -bilateral, telefónica, consecutivas breves, susurrado, reformulaciones orales, traducción a vista, toma de notas-, pero también traducirá - recordemos, con inclusión de contenidos verbales y no verbales de los contenidos comunicados-, resumirá por escrito, o a veces registrará llamadas.

\section{DIFICULTADES GENÉRICAS DE LA IET Y HERRAMIENTAS DISCIPLINARES COADYUVANTES}

En los apartados anteriores se ha hecho mención de las dificultades genéricas más importantes de una IET, como el factor audio y su escucha activa, la variabilidad de las partes implicadas, la colocación 'externa y ajena' del intérprete respecto a la interacción que se produce al teléfono, o el trabajo monosensorial propio de una interpretación telefónica. Hemos dejado pendiente para este apartado específico el asunto de la bilateralidad en IET y las dificultades de carácter lingüístico, pragmático y sociolingüístico más frecuentes.

En lo referente al audio, pilar sobre el que se fundamenta toda la IET, se han citado las dificultades que podríamos denominar extrasituacionales, es decir, aquellas puramente técnicas, como la cobertura intermitente, que tiene poca solución, o los ruidos de fondo, que a veces pueden tratarse con aplicaciones informáticas y software a disposición en sala de escuchas. También se han mencionado dificultades que surgen en un plano inter-situacional (entre el intérprete y la interacción escuchada), como el volumen de voz o la velocidad de discurso, solucionables con los instrumentos informáticos. Por último, encontramos dificultades de tipo intra-situacional, es decir, dentro de la interacción escuchada, y que pueden ser numerosas y de varia índole: voces superpuestas, intervenciones desordenadas, interrupciones constantes, carga emocional excesiva en las voces - llanto asustado mientras se habla, por ejemplo- o número de voces superior a lo habitual, porque hay que tener en cuenta que la interacción al teléfono consta de dos partes, lo que no significa que sean necesariamente dos las personas que se hablan - puede tratarse de dos personas con un interlocutor, o incluso varias personas con dos, etc. En este último caso referido, el intérprete puede tener problemas a la hora de identificar las voces y lo que dice cada una de ellas, un asunto que puede llegar a ser delicado y al que el intérprete deberá prestar toda la atención posible. En cualquier caso, los problemas de audio existirán siempre, de uno u otro tipo y en mayor o menor grado, por lo que conviene que el intérprete acostumbre su oído a todo tipo de circunstancias, para potenciar en lo posible la habilidad de la escucha activa, tema tratado en puntos anteriores.

Otra cuestión que crea alguna que otra dificultad es la variabilidad de las partes; hemos subrayado la variabilidad de los agentes en sala de escuchas, que pueden ser varios o uno solo, o la variabilidad de los mismos derivada de sus turnos de trabajo. Sin embargo, no hemos afrontado aún la variabilidad de las partes al otro lado del teléfono. En este punto, hay que considerar que aunque sea reducido el número de teléfonos intervenidos $-5,6$ ó 7 , por ejemplo- no se llaman únicamente entre ellos, sino que comunican también con familiares, amistades, compañeros de trabajo, etc. En un encargo con 5 números interceptados pueden surgir más de 16 voces, $\mathrm{y}$ todas han de ser identificadas aunque al final el trabajo de seguimiento afecte a unas 8 ó io de ellas, o también puede 
ocurrir que vayan cambiando a lo largo de la investigación los números intervenidos, o sea, que aumente, cambie o disminuya el número total de interceptados. Por último, subrayamos una ulterior dificultad: recordamos que en las intervenciones contamos con un número intervenido y propietario/a del mismo, lo cual no significa forzosamente que este use ese teléfono en exclusiva, ya que a veces puede intercambiarse, prestarse o usarlo puntualmente otra persona distinta a la habitual.

Ante toda esta variabilidad constante, al teléfono y en sala, es muy fácil perder la concentración necesaria en las ET; como prevención, estudiar las relaciones que se van descubriendo al otro lado del teléfono y prestar mucha atención a los 'comportamientos comunicativos'y los 'rasgos personales básicos de la voz' pueden ser dos herramientas muy útiles para el intérprete en el trabajo de identificación de voces, como lo será también practicar la toma de notas de forma ordenada y precisa. Por lo que respecta al aspecto relacional en sala, se remite a González Rodríguez (20I4a: 2IO-2II) en la que se propone la aplicación de parámetros de mediación para mejorar aspectos relacionales con los agentes y conseguir optimizar el trabajo de colaboración con ellos.

Anteriormente se aludía al hecho de que la interpretación bilateral operada en las IET mostraba ciertas peculiaridades respecto a su bidireccionalidad; efectivamente, la interacción en sala de escuchas - presencial con una de las partes - presenta todas las características clásicas de una IB, a excepción de la gestión de turnos; el intérprete realiza operaciones bidireccionales con cambio de código lingüístico hacia la parte presente — agente/s—, y de alguna forma, las peticiones del agente 'actúan' como turno, pudiendo influir en la escucha de la interacción telefónica, aunque, lógicamente, no afectará a los contenidos de la interacción. El esquema de la bilateralidad presentada es el siguiente:



Como se puede observar en el diagrama anterior, la 'bilateralidad completa' ha sido representada por la flecha con doble punta, y corresponden no sólo a las interacciones de intérprete con agente, sino también a la interacción entre las partes al teléfono; por su parte, la bidireccionalidad del intérprete en su trabajo bilateral - parte presencial / partes al teléfono- se indica por un lado completa, mientras que con las partes al teléfono se representa con una flecha el input que recibe, y con la flecha a puntos se simboliza el trabajo de selección, o de identificación, o de re-construcción que le puede ser solicitado por los agentes. En cualquier caso, la interacción entre las partes al teléfono - una bidireccionalidad dentro de su propia bidireccionalidad operada - es la que 'descoloca' al intérprete, y la que le puede causar más quebraderos de cabeza.

$\mathrm{Si}$ nos concentramos precisamente en esa interacción, los interlocutores al teléfono, podemos analizar numerosas dificultades de carácter lingüístico que el intérprete deberá afrontar. En los casos de IET experimentados se ha trabajado con el par de idiomas español-italiano, pudiendo considerar el primero como lengua original o de partida (LO) y el segundo como lengua de llegada o terminal (LT). Esta circunstancia hace que el trabajo resulte más complejo potencialmente, ya que el español, como lengua 
internacional que es, presenta una gran multitud de variantes de uso, mientras que el caso contrario - italiano LO y español LT - hubiera 124 resultado de seguro diferente. ${ }^{2 \mathrm{I}}$ Normalmente el intérprete seleccionado tiene como lengua materna el idioma previsto en interceptación, una condición que da seguridad y confianza a las autoridades como herramienta eficaz en las ET, aunque en el ambiente de la interpretación y la traducción sabemos muy bien que ser un 'lengua materna' es muy útil, pero no es lo único que se necesita o que valida a una persona para ejercer estas profesiones. En Italia existe una suerte de conciencia sobre la internacionalidad del español, aunque se trata de una 'conciencia colectiva' basada en típicos tópicos, como por ejemplo, que un ciudadano español, por el simple hecho de serlo, tiene un 'conocimiento más exacto' de la lengua española respecto a un ciudadano de cualquier otro país hispanófono; en este sentido, conviene aclarar desde un principio con los responsables de la investigación judicial ciertas premisas inherentes a nuestro oficio y experiencia adquirida, del todo independientes de la nacionalidad del individuo. ${ }^{22}$ Una vez apuntada ésta y otras cuestiones en la entrevista para el encargo de una IET, es conveniente que el intérprete se informe muy bien sobre el caso que le ocupará y sobre las personas a las

${ }^{21}$ A propósito de los pares de idiomas presentes en una ET, subrayamos también la presencia frecuente de fenómenos de interferencia y/o alternancia de código lingüísticos en escucha; en los dos encargos de ET han aparecido a menudo interferencias con el italiano en interacciones telefónicas en español, debidas en parte a la proximidad de las lenguas, y en parte a la inclusión del italiano por ser la lengua franca, la 'lengua local' hablada donde se ubica la interacción.

${ }^{22}$ No se trata sólo de una cuestión de principios: las premisas iniciales en este sentido influirán decisivamente en la percepción que se tendrá de la figura del intérprete, una cuestión importante a la que se están dedicando estudios específicos y que determina la posible valoración o evaluación de la interpretación realizada. que escuchará en interceptación; Olalla (2006: 242-246) a propósito del intérprete policial y el intérprete de ET expone reflexiones muy acertadas sobre cuestiones metodológicas y observaciones de carácter lingüístico-cultural que ayudan al intérprete de ET, como por ejemplo indagar sobre «el lugar de origen de los investigados» o «en qué nivel cultural» se sitúan (244), «saber el argot del delincuente» (245), etc. En realidad, la autora está haciendo referencia a parámetros o indicadores de carácter sociolingüístico que el intérprete debe activar para 'conocer' las voces en escucha: identificar los ya nombrados elementos diatópicos - características de la lengua hablada por extensión geográfica-, diastráticos —uso de la lengua según el nivel sociocultural del hablante-, diafásicos —registros lingüísticos_- etc. Sobre la cuestión del argot, no cabe duda de que si el intérprete ha trabajado anteriormente con el tema de tráfico de drogas juega con ventaja por experiencia adquirida, pero no contar con ella no le imposibilita afrontar su trabajo, ya que seguramente dispondrá del asesoramiento de los agentes que le ayudarán a 'abrir' metáforas, estudiará con cuidado aspectos jergales, y prestará atención a los coloquialismos.

Indudablemente, la lista de fenómenos lingüísticos que podríamos encontrar en una IET sería muy extensa, y variada, y podría resultar muy interesante, como también podría ser útil cualquier intento de creación de un glosario temático por tipología de delito. Sin embargo, estas herramientas podrían tener sólo un uso puntual, que difícilmente podríamos emplear o extrapolar, por ejemplo, a otras zonas hispanófonas, a otros ambientes italianos, a otras situaciones, etc. Por otra parte, concentrarse en argots o asuntos similares puede resultar inútil, en tanto que no todas las personas que delinquen presentan un nivel sociocultural bajo, han 
crecido en la pobreza o han convivido siempre con el crimen, sino que podemos encontrarnos en escuchas personas y/o personajes de altísimo nivel sociocultural, con un uso de la lengua apropiado o incluso excelente, con profesiones prestigiosas, etc., porque el 'delincuente de profesión' tiene un perfil cada vez más variado y diversificado. Una reflexión similar cabría respecto al registro lingüístico, y en este campo, el intérprete ha de ser muy hábil, ya que esta cuestión se convertirá además en una dificultad más que afrontar en las operaciones de transferencia como elemento asimétrico que habrá que reajustar, es decir, deberá 'adaptar', por ejemplo, una serie de improperios o de marcadas formas coloquiales al agente de turno para que conste en acta, en un registro oficial. ${ }^{23}$

En resumen, nuestra propuesta para afrontar dificultades de carácter lingüístico de 'nuestras voces' se basa en la identificación de perfiles, como 'ubicarse' en el mapa lingüístico, detectar elementos diastráticos, y estar muy atentos a los planos léxicos - por posible variabilidad de significados- y morfológicos — que nos ayudan a trabajar con sociolectos o idiolectos-, pero las herramientas principales serán aquellas que nos ayuden a comprender las intenciones comunicativas de los interlocutores telefónicos. En realidad, la mayor dificultad que encontrará el intérprete de ET tiene que ver sustancialmente con las intenciones comunicativas: la comunicación criptada, la voluntariedad de comunicar algo 'sin decirlo' es el eje principal de la mayoría de las interacciones sobre intenciones delictivas o sobre actos delictivos. Por lo tanto, se propone que el intérprete opere y realice su trabajo

23 Un ejemplo: si no se considera información relevante para el caso, un jocoso relato sobre un examen ginecológico sufrirá modificaciones en su registro lingüístico al resumirlo para el agente y pasarlo a traducción resumida en registro. desde la perspectiva de la tridimensionalidad de la comunicación (Poyatos, I994), aplicando a su vez elementos metodológicos propios de la mediación intercultural (Giménez Romero, 200I).

\section{IMPLICACIONES DE LA IET PARA EL INTÉRPRETE}

En este apartado se hace necesaria la referencia al trabajo de Handi y Ortigosa (20II) sobre el impacto emocional que suponen los relatos negativos en los intérpretes. Concordamos con todo lo expuesto en el estudio citado, ya que la práctica totalidad de los aspectos tratados en el mismo son aplicables e identificables en el trabajo del intérprete de ET. Como ya hemos visto, en este tipo de trabajo las prestaciones del intérprete deben ir mucho más allá de lo que se suele entender habitualmente por interpretar: trabajar en interacciones 'con partes múltiples' y con una de ellas 'a ciegas', sin posibilidad de intervención en la misma, con tiempos indefinidos, en situaciones ocasionales de emergencia, entrando 'en línea directa', etc, generan ciertamente una carga de estrés importante que el intérprete deberá aprender a gestionar lo antes posible.

En un trabajo de intervenciones o interceptaciones telefónicas el intérprete interpreta, pero también se 'descubre' espiando, una situación ineludible en este tipo de encargo que puede comportarle, además de estrés, una cierta incomodidad durante la realización de sus tareas. Sin duda alguna, interpretar espiando, o espiar interpretando no es cosa fácil, al tratarse de dos actividades que desde la lógica de la metodología de la interpretación no son compatibles - el intérprete debe co-participar de alguna forma en la interacción que interpreta-, por lo que se ve obligado a reinventarse, adaptarse o adoptar 
otro tipo de estrategias, y a prestar mucha atención a esa incomodidad que mencionábamos, ya que podría incidir negativamente en sus operaciones - mermar su habilidad de escucha activa, restar capacidad de concentración, etcétera. Por otra parte, espiar a través de escuchas telefónicas significa que el intérprete se introduce en las vidas de los interceptados hasta niveles insospechados, a veces llega a tocar la intimidad de las personas, sus preocupaciones, sus más íntimos deseos, lo que conlleva un peligro claro de implicación: vigilar la parte psicológica, las empatías que puedan crearse, deshacerse de incomodidades, extrañezas varias y de posibles implicaciones deben ser prioridad absoluta para el intérprete de ET, como lo debe ser también el 'sobreponerse' al gran peso que supone tomar conciencia de la enorme responsabilidad de su tarea, y comprender que su trabajo no sólo es decisivo, sino que además es decisorio.

\section{CONCLUSIONES}

El propósito hasta estas líneas era el de presentar las características de la interpretación para/en escuchas telefónicas, definir el marco disciplinar utilizado en ellas y analizar su metodología operacional. A partir de aquí, se expondrán algunas propuestas consideradas útiles para el objeto de este estudio, con la intención de contribuir en la construcción de 'buenas prácticas' en el trabajo de intérprete de escuchas telefónicas.

Partimos de la base de que los encargos de ET experimentados en Italia y que han sido objeto de análisis responden perfectamente tanto a la legislación italiana que disciplina la cuestión de intervenciones telefónicas como a la normativa referente a los servicios del intérprete en los procedimientos judiciales. Esta premisa no impide que en la práctica cotidiana se produzcan leves diferencias en los mecanismos y

metodología de trabajo de una región a otra del territorio italiano, una diversidad que obedece sustancialmente a la necesidad de amoldarse a los recursos disponibles y a la posibilidad de adaptarse a las circunstancias de cada caso, como por ejemplo, incluir o no operaciones de transcripción atendiendo a la urgencia, o a la complejidad, o a las dificultades de la investigación en cuestión. En cualquier caso, y considerando todo lo expuesto anteriormente, llama la atención que no se haya incluido en la normativa sobre escuchas un apartado dedicado a requisitos necesarios, baremos de evaluación curricular y baremos de selección de los candidatos para un encargo de interpretación de escuchas telefónicas, ni se haya concebido la posibilidad de integrar un periodo preparatorio o de formación que introduce al intérprete en los peculiares mecanismos de una IET.

En este sentido, se señala la necesidad de incluir una suerte de reglamentación que regule e implante a nivel nacional un sistema de selección de intérpretes para encargos de ET, combinado con un periodo de formación introductoria seria y específica, para garantizar y/o certificar objetivamente la profesionalidad y la calidad de los servicios prestados por los intérpretes, condición sine qua non para todo sistema judicial y el buen hacer de la Justicia.

La cuestión de la formación para una IET la podemos enmarcar en cualquier caso en programas de formación específicos para intérpretes judiciales y/o intérpretes policiales: los interrogatorios en penitenciarías, por ejemplo, tienen muchos puntos en común con las escuchas telefónicas, por lo que se podría pensar en concebir un programa único de formación en el que se incluyera metodología y análisis de tareas relativas a todo el ámbito policial y judicial, capitalizando así recursos y herramientas aplicables en una u otra modalidad de interpretación. 
Si pudiéramos imaginar un cuadro ideal para un proyecto formativo, lo más adecuado sería contar con la docencia de intérpretes experimentados en las distintas modalidades de interpretación de este ámbito específico, así como de 'operadores del sector' - jueces, agentes, etc.con experiencia adquirida en/con la asistencia de intérpretes y traductores, en co-presencia docente incluso. El público al que iría dirigido el/los curso/s formativos procedería de un registro o listado de colaboradores habituales con la justicia a nivel provincial, o regional, o por qué no, nacional. La cuestión de 'en/para qué idiomas' resultaría secundaria, desde el momento en que la formación se orienta hacia la metodología de trabajo y las herramientas y mecanismos implicados, aplicables a todo par de lenguas que puedan surgir en procedimientos judiciales en cada país.

El corte de los programas formativos podría ir en perfecta consonancia con la directiva UE 64/201o del Parlamento Europeo y del Consejo Europeo $^{24}$ mencionada anteriormente, una directiva que no sólo propone sino que además, como tal, conmina a sus Estados Miembros a adoptar los contenidos de la misma.

Dicha directiva, registrada como Acto legislativo en el Diario Oficial de la Unión Europea con fecha 20 de octubre de 2010 , regula el derecho a interpretación y a traducción en los procesos penales; además de alumbrar a los Estados Miembros sobre la importancia de estas disciplinas para la Justicia, conmina a los mismos a incorporar dicha directiva al derecho interno de cada uno de ellos antes del 27 de octubre de 20I3; esta directiva establece normas relativas al derecho a interpretación y a traducción en los procesos penales ante las autoridades

${ }_{24}$ Texto completo disponible en: http://eur-lex.europa.eu/LexUriServ/LexUriServ.do?uri=OJ:L:2010:280:000I :ooo7:es:PDF judiciales (art. 2 interpretación y art. 3 traducción), incluidos interrogatorios, vistas judiciales $\mathrm{y}$ audiencias intermedias, lo que significa que la IET queda también comprendida. Se trata de un gran paso adelante - interesa a nada más y nada menos que 28 naciones-, ya que normaliza los mecanismos por los que un Estado debe, y subrayamos por su importancia, comprobar la necesidad de asistencia de un intérprete, la posibilidad de presentar una reclamación por escasa calidad de la interpretación, la posibilidad de inclusión del uso de las tecnologías - IT, videoconferencia-, saca a colación la cuestión de los costes de interpretación y de la calidad de la interpretación, instando a elaborar un «registro de traductores e intérpretes independientes debidamente cualificados» (art. 5.2) y a formar a jueces, fiscales y personal judicial para que presten una atención especial a las particularidades de la comunicación con la ayuda de un intérprete, para que ésta sea efectiva y eficaz (art.6). El asunto de formación para 'operadores del sector', como también indica Pajarín Canales (20II) en su trabajo dedicado a la percepción del papel del intérprete ante los tribunales por parte de los juristas, resulta de extrema importancia; acercar a los operadores de la Justicia a la figura del intérprete y sensibilizarlos sobre la complejidad de las tareas de los intérpretes y traductores favorecerían automáticamente el propio ejercicio profesional, el de unos - jueces, agentes, juristas en general-, como el de otros - traductores e intérpretes-, y por ende, la Justicia ganaría calidad y eficacia. Sin duda alguna, una Justicia así es lo que todos los ciudadanos del mundo quisieran para sus sociedades, aunque al final, nos quedemos con las palabras de Handi (Rincón, 20I2): «Si estoy en un país extranjero y tengo un problema, antes de elegir el mejor abogado o al mejor juez, pediría al 
mejor intérprete. Como dijo López de Vega, antes de ser defendido, prefiero ser entendido».

\section{REFERENCIAS}

Collados Aís, A. Fernández Sánchez M. (200I). Manual de interpretación bilateral. Granada: Comares.

Corrêa de Carvalho J. (2007) «Intervención de las comunicaciones telefónicas en España» [en línea] en Noticias Juridicas. <http://noticias. juridicas.com/articulos/65-Derecho-ProcesalPenal/2007II-20202058458757.html>, [consulta: I0.08.20I4].

Giménez, Romero, C. (200I). «Modelos de mediación y su aplicación en mediación intercultural». Revista Migraciones, Madrid: Universidad Pontificia de Comillas, ıо: 59-ıाo.

González Rodríguez, M. J. (2006a). «De lo escrito a lo oral y viceversa: una forma de ordenar el desorden en mediación», en G. Bazzocchi y P. Capanaga (eds.), Mediación lingüistica de lenguas afines: español/italiano. Bologna: Gedit, 245-272.

González Rodríguez, M. J. (2006b). «El 'don de la ubicuidad' en la interpretación bilateral» [en línea]. MediAzioni. <http://www.mediazioni. sitlec.unibo.it/images/stories/PDF_folder/document-pdf/2006/articolizoo6/1\%2ogonzlez\%20 rodrguez.pdf> [consulta: o6/o8/2013].

González Rodríguez, M. J. (2010). «E1 'nuevo mundo' de la mediación lingüística y cultural: a la 'reconquista' del territorio desde la interpretación bilateral», en M. Carreras y M.E. Pérez, (eds.), La mediación lingüistica y cultural y su didáctica. Un nuevo reto para la Universidad. Bologna: Bononia University Press, 63-92.

González Rodríguez, M. J. (20II). «La diversidad homogénea de la interpretación bilateral: reflexiones sobre dos casos específicos en tribunales italianos y comparación con un caso sanitario español», en Valero Garcés, C. (coord. y ed.), Traducción e interpretación en los servicios públicos en un mundo INTERCoNEcTado. Alcalá de Henares: Universidad de Alcalá Servicio de Publicaciones, I88-I96. ISBN: 978-84-8I38-9I3-5.

González Rodríguez, M. J (2014a). «Formas de mediación en el trabajo de intérprete de escuchas telefónicas», en Valero Garcés, C. (coord. y ed.),
(RE)considerando ética e ideología en situaciones de conflicto. Alcalá de Henares: Universidad de Álcala Servicio de Publicaciones, 205-2I4. ISBN: 978-84-г6r33-08-06.

González Rodríguez, M. J. (20I4b). «La interpretación bilateral como disciplina de especialización: formación y perspectivas en investigación», en SKOPOS, Revista internacional de traducción e interpretación, vol. 5, 59-76, ISSN: 255-3703.

González Rodríguez M. J. (en prensa). «Reflexiones sobre la interpretación de escuchas telefónicas como especialización de alto rendimiento de la interpretación telefónica», en SKOPOS, Revista internacional de traducción e interpretación, vol. 6.

Handi, E.B., Ortigosa M. D. (20II). «El impacto emocional de los relatos negativos en los intérpretes», en Valero Garcés, C. (coord. y ed.), Traducción e interpretación en los servicios públicos en un mundo INTERcoNEcTado. Alcalá de Henares: Universidad de Alcalá Servicio de Publicaciones, 20-30. ISBN: 978-84-8138-9I3-5.

Kelly, N. (2008). Telephone Interpreting: A comprehensive guide to the profession. Massachusetts: Trafford Publishing.

López-Fragoso Álvarez, T. (I99I). Las intervenciones telefónicas en el proceso penal. Madrid: Constitución y Leyes.

Marco Urgell, A. (2010). La intervención de las comunicaciones telefónicas: grabación de conversaciones propias, hallazgos casuales y consecuencias jurídicas derivadas de la ilicitud de la injerencia. Tesis doctoral, Universidad Autónoma de Barcelona. < http:// www.tdx.cat/bitstream/handle/10803/32087/ amuider.pdf;jsessionid=AI93I2I2ECDE05 DI5 F 9588E99722 E955.tdx2? sequence $=\mathrm{I}>$ [consulta: 25/o7/2013].

Obón Díaz, A. (2004), «La intervención telefónica y su adecuación al paradigma constitucional», en Revista General de legislación y jurisprudencia, vol. 2,307-315, IS SN: 02108518.

Obón Díaz, A. «La intervención telefónica y su adecuación al paradigma constitucional», [en línea]. Noticias Jurídicas. Noviembre 2004, <http:// noticias.juridicas.com/articulos/65-DerechoProcesal-Penal/2004II-955I369I0432791.html> [consulta: Io.08.20I4].

Olalla Fernández, P. (2006) «El intérprete en la investigación policial». En Raga, F. y Valero Garcés, C., Revista Española de Lingüística Aplicada 
(RESLA). Monográfico Retos del s. XXI para la lingüistica aplicada: nuevo mapa lingüistico-cultural de la Peninsula Ibérica (I) 239-248.

Ortega Herráez, J. M. (20II) «El uso, no uso y abuso de las nuevas tecnologías en la práctica profesional de la traducción y de la interpretación en contextos policiales», en Valero Garcés, C. (coord. y ed.), Traducción e interpretación en los servicios públicos en un mundo INTERcoNEcTado. Alcalá de Henares: Universidad de Alcalá Servicio de Publicaciones, 93-II5. ISBN: 978-84-8I38-9I3-5.

Pajarín Canales, A. (20II) «La percepción del papel del intérprete ante los tribunales por parte de los juristas: análisis de expectativas y utilización de las TIC para su formación y concienciación», en Valero Garcés, C. (coord. y ed.), Traducción e interpretación en los servicios públicos en un mundo INTERcoNEcTado. Alcalá de Henares: Universidad de Alcalá Servicio de Publicaciones, II6-I25. ISBN: 978-84-8138-913-5.

Poyatos, F. (I994). La comunicación no verbal II. Paralenguaje, kinésica e interacción. Madrid: Istmo.

Poyatos, F. (I998) «Los silencios en el discurso vivo y en la literatura: para el estudio realista del lenguaje y su entorno», en Oralia: análisis del discurso oral, vol. I, ISS N: 1575-I430, pp. 47-70.

Rincón Borobia, S. «El trabajo de los traductores fue un éxito en el juicio del II-M» [en línea]. La Opinión de Tenerife. Portada Tenerife. 27 febrero $20 \mathrm{OI} 2$, <http://www.laopinion.es/portada/2012/o2/27/ trabajo-traductores-exito-juicio-II-m/399179. html> [consulta: 3 I junio 20I3]. 